Vol. 1 No. 2 September 2021 e-ISSN : 2797-3344 P-ISSN : 2797-3336

\title{
IMPLEMENTASI RPP INTEGRATIF MEMBENTUK KARAKTER KEBANGSAAN UNTUK MEWUJUDKAN BUDAYA LITERASI SISWA
}

\author{
R. NOVIYATI HASYIANI \\ SMP Negeri 1 Sampang \\ Email : Noviyati1970@gmail.com
}

\begin{abstract}
ABSTRAK
Gerakan Literasi Sekolah yang dicanangkan oleh Kemendikbud di lingkungan sekolah tidaklah mudah untuk dilaksanakan di sekolah SMP Negeri 1 Sampang. Siswa sering kali mengatakan sulit untuk menyelesaikan tugas dari guru. Hal ini terbukti ketika menuliskan laporan kegiatan seringkali siswa mengatakan saya tidak bisa, bagaimana saya memulainya dan dari mana saya memulainya. Ketidak mampuan siswa dalam berliterasi disebabkan oleh minat baca yang sangat rendah karena siswa lebih banyak menghabiskan waktunya dengan gawai. Disini peneliti selaku guru IPS melakukan strategi kegiatan pembelajaran berintegrasi dengan mata pelajaran PPKn, PAI, Bahasa Indonesia, dan seni Budaya, Best practice menggunakan metode Discovery Learning melalui media pemutaran film documenter peristiwa G30S/PKI. Materi RPP Integratif dengan tema Perkembangan Politik di Indonesia kelas IX semester ganjil mampu mewujudkan budaya literasi di SMP Negeri 1 Sampang. Hal ini dibuktikan dari peningkatan jumlah siswa yang mampu menyelesaikan tugas sebesar $88 \%$ yaitu dari $12 \%$ menajadi $100 \%$
\end{abstract}

Kata Kunci: RPP Integratif, Budaya Literasi

\section{ABSTRACT}

The School Literacy Movement launched by the Ministry of Education and Culture in the school environment is not easy to implement in SMP Negeri 1 Sampang. Students often say it is difficult to complete assignments from the teacher. This is evident when writing activity reports students often say I can't, how do I start and where do I start. The inability of students in literacy is caused by very low interest in reading because students spend more time with gadgets. Here the researcher as a social studies teacher carries out a strategy of integrated learning activities with Civics, PAI, Indonesian language, and cultural arts subjects, Best practice using the Discovery Learning method through the media screening of the G30S/PKI event documentary. Integrative RPP material with the theme Political Development in Indonesia for class IX odd semesters is able to create a literacy culture at SMP Negeri 1 Sampang. This is evidenced by the increase in the number of students who are able to complete assignments by $88 \%$, from $12 \%$ to $100 \%$.

Kata Kunci: Integrative RPP, Literacy Culture

\section{PENDAHULUAN}

Pencanganagan Gerakan Literasi Nasional pada tahun 2016 oleh Kementrian Pendidikan dan Kebudayaan salah satu program didalamnya adalah kegiatan Gerakan Literasi Sekolah. Gerakan Literasi Sekolah (Kemendikbibud, 2016) adalah gerakan literasi dimana kegiatan ini dilakukan di lingkungan sekolah yang melibatkan siswa, pendidik, tenaga kependidikan, serta orang tua dalam menampilakn praktik literasi dan menjadikannya sebagai kebiasaan serta budaya di lingkungan sekolag. Adapun tujuan dari Gerakan Lietrasi Sekolah ingin menjadikan sekolah sebagai wadah pembelajran berbudaya literasi, dan membentuk warga sekolah yang literat baik dalam hal membaca, menlis, numerasi, sians, digital, finansial, budaya serta kewrganegaraan. Dengan sasaran kegiatan verada pada tingkat pendidikan dasar dan menengah.

Dari data Perpustakaan Nasional (Perpunas) tahun 2020 tentang Indeks Kegearan Membaca, minat baca masyarakat Indonesia berada pada posisi 55,74 persen posisi ini menunjukkan minat baca masyarakat Indonesia verada dalam kategori sedang. Sebuah penelitian International Education Achiement (IEA) menyatakan rendahnya minat baca pada 


\section{Vol. 1 No. 2 September 2021 e-ISSN : 2797-3344 P-ISSN : 2797-3336}

anak disebabkan oleh adanya perkembangan teknologi yang semakin canggih karena karena anak lebih memilih mengahabiskan waktu dengan gawai canggih daripada membaca (Ane, 2015). Selain itu kurang adanya rangsangan dan motivasi agar siswa mau untuk membaca dalam mencari informasi.

Tantangan ini menuntut guru sebagai pendidik wajib membuat rancangan pembelajaran yang dapat memotivasi siswa mewujudkan siswa sebagai generasi muda yang berbudaya literasi. Rancangan pelaksanaan pembelajaran yang disingkat RPP merupakan rancangan yang wajib dilakukan oleh guru sebagai pendidik sebelum melaksanakan kegiatan pembelajaran. Peraturan Menteri Pendidikan dan kebudayaan Nomor 22 tahun 2016 tentang standart Proses disebutkan bahwa setiap pendidik berkewajiban menyusun rencana pelaksanaan pembelajaran secara lengkap dan sistematis agar pembelajran berlangsung secara interaktif, inspiratif, menyenangkan, menantang dan dapat memberikan memotivasi pada siswa agar bisa berpartisipasi aktif dalam kegiatan pembelajaran serta dapat memberikan ruang yang cukup bagi siswa melalui strategi yang tepat dan benar maka akan meningkatkan ketercapaian kompetensi lulusan yang efisiensi dan efektifitas.

Menurut Nurdin \& Andriantoni (2016:94) berpendapat bahwa: Rencana Pelaksanaan Pembelajaran merupakan perencanaan jangka pendek untuk merencanakan kegiatan pembelajaran yang akan dilakukan. Daryanto (2014:84) menyebutkan bahwa rencana Pelaksanaan Pembelajaran (RPP) adalah rencana yang memberikan gambaran alur dan pengorganisasian dari kegiatan pembelajaran guna mencapai kompetensi dasar yang merujuk pada Stándar Isi dan penjabaran dalam silabus.

Dua fungsi dasar yang melekat pada RPP seperti disebutkan dalam Nurdin \& Andrianto (2016:94) yaitu (1) fungsi perencanaan. Fungsi ini merupakan fungsi dasar yang membantu guru dalam mempersiapkan pembelajaran lebih matang baik secara tertulis ataupun tidak tertulis. (2) Fungsi efektif. Maksud dari efektif disini pembelajaran yang direncanakan terlebih dahlu akan berjalan dengan baik dan sesuai dengan tujuan dari pembelajaran tersebut.

Prinsip-prinsip dalam menyusun RPP hendaknya memperhaikan hal-hal berikut: (1) pahami setiap karater; (2) libatlkan siswa dalam aktif belajar; (3) kegiatan pembelajaran berpusat pada siswa sehingga terbentuk motivasi, minat, kreativitas, inisiatif, inspirasi, inovasi dan kemandirian dalam proses pembelajaran; (4) membudayakan baca tulis; (5) memuat umpan balik dalam bentuk penguatan, pengayaan dan remidi; (6) antara KD, materi pembelajaran, kegiatan pembelajaran, indikator pencapaian kompetensi, penilaian dan sumber belajar ada keterkaitan sebagai satu kesatuan utuh sebagai bentuk pengalaman belajar siswa; (7) perlu adanya keterpaduan lintas mata pelajaran dan keragaman budaya menjadi pembelajaran tematik dan terpadu; (8) berintegrasi secara sistematis dan efektif mempertimbangkan situasi dan kondisi dalam penerapan teknologi informasi dan lomunikasi.

Di tempat kelas yang penulis ajar, budaya literasi sangatlah rendah, ketika siswa diberi tugas untuk membuat karya tulis selalu ada pernyataan saya tidak bisa, bagaimana memulainya, dan darimana memulainya, selain itu ada rasa tidak percaya dalam diri siswa dengan tulisan yang telah mereka buat. Dari kelas tersebut hanya 12 persen siswa yang mampu menyelesaikan tulisan. Kenyataan ini menunjukkan minat dan kemampuan siswa perlu dimotivasi dan tindakan nyata yang harus dilakukan oleh guru mewujudkan budaya literasi sekolah.

Untuk mewujudkan budaya literasi di sekolah penulis telah merancang kegiatan pembelajaran dengan mengintegrasikan mata pelajaran IPS, PPKn, PAI,Bahasa Indonesia,dan Seni Budaya. Materi ang diberikan tentang nilai-nilai kebangsaan dan agama yang harus tertanam dalam jiwa generasi muda. Media pembelajaran berupa pemutaran film dokumenter peristiwa G30S/PKI. Siswa diminta untuk menonton jalannya peristiwa G30S/PKI dan menganalisa film tersebut mulai dati latar belakang peristiwa, dampak peristiwa terhadap nilainilai Pnacasila dan bagaimana mengantisipasi jika gerakan komunis datang kembali ke negara Indonesia, selain itu siswa diminta untuk mengekspresikan salah satu tokoh yang ada dalam film dalam bentuk cerita dan dalam bentuk gambar berupa sikap mereka terhadap tokoh tersebut seperti sikap marah, suka atau suka. 
Vol. 1 No. 2 September 2021 e-ISSN : 2797-3344 P-ISSN : 2797-3336

Dari hasil kegiatan pembelajaran menggunakan rancangan pelaksanaan pembelajaran integrasi terbukti siswa mampu membuat laporan tertulis. Penulis selaku guru koordinator RPP Integrasi merupakan cara yang tepat untuk diterapkan di sekolah dalam mewujudkan budaya literasi sekolah.

\section{METODE PELAKSANAAN}

Jenis penelitian ini merupakan praktik baik bersifat deskriptif yang menggambarkan implementasi RPP integrative mampu mewujudkan budaya literasi di sekolah. Praktek baik ini dilaksanakan pada semester ganjil tahun pelajaran 2021/2021 di bulan September 2020 di SMP Negeri 1 Sampang jalan Wijaya Kusuma No.2 Sampang, dilakukan pada siswa kelas IX-I SMP Negeri 1 Sampang dengan jumlah siswa sebanyak 34 orang siswa terdiri atas 18 orang siswa laki-laki dan 16 orang siswa perempuan tahun ajaran 2020/2021. Praktek baik ini terdiri dari lima mata pelajaran yaitu PPKn, IPS, PAI, Bahasa Indonesia dan Seni Budaya. Materi yang digunakan perkembangan politik di Indonesia kelas IX semester Ganjil Tahun 2020/2021 dengan tema membentuk karakter kebangsaan. Metode yang digunakan Discovery Learning dengan media pembelajaran pemutaran film documenter G30S/PKI. Obyek penelitian adalah mengimplementasikan RPP integratif untuk mewujudkan budaya literasi di SMP Negeri 1 Sampang. Tema pokok pembelajaran integratif ini membentuk karakter kebangsaan siswa adapun Indikator yang ingin dicapai adalah (1) siswa mampu menganalisa perkembangan politik di Indonesia; (2) siswa mampu menjelaskan dinamika nilai-nilai pancasila sesuai dengan perkembangan jaman; (3) siswa mampu membiasakan diri bersikap jujur; (4) Menyimpulkan struktur teks cerita pendek yang didengar atau dibaca; (5) Mendeskripsikan prosedur berkarya seni lukis dengan berbagai bahan dan Teknik; (6) siswa mampu membuat laporan tertulis analisa film dokumenter dalam membentuk karakter kebangsaan.

\section{HASIL DAN PEMBAHASAN}

\section{Hasil}

Hasil dari kegiatan pembelajaran sebelum menggunakan RPP Integratif (TugasI)dan setelah menggunakan RPP Integratif (Tugas II) diperoleh data siswa yang menyelesaikan tugas Laporan Tertulis sebagai berikut:

Tabel 1 Rekapitulasi Penyelesaian Tugas I

\begin{tabular}{llll}
\hline No. & Keterangan & Tugas I & \\
\cline { 3 - 4 } & & Jumlah Siswa & Prosentase \\
\hline $\mathbf{1}$ & Selesai & 4 & $12 \%$ \\
\hline $\mathbf{2}$ & Belum selesai & 20 & $59 \%$ \\
\hline $\mathbf{3}$ & $\begin{array}{l}\text { Tidak } \\
\text { membuat }\end{array}$ & 10 & $29 \%$ \\
\hline
\end{tabular}

Tabel 2 Rekapitulasi Penyelesaian Tugas II

\begin{tabular}{llll}
\hline No. & Keterangan & Tugas II & \\
\cline { 3 - 4 } & & Jumlah Siswa & Prosentase \\
\hline $\mathbf{1}$ & Selesai & 34 & $100 \%$ \\
\hline $\mathbf{2}$ & Belum selesai & - & - \\
$\mathbf{3}$ & Tidak & - & - \\
& membuat & & \\
\hline
\end{tabular}


Vol. 1 No. 2 September 2021 e-ISSN : 2797-3344 P-ISSN : 2797-3336

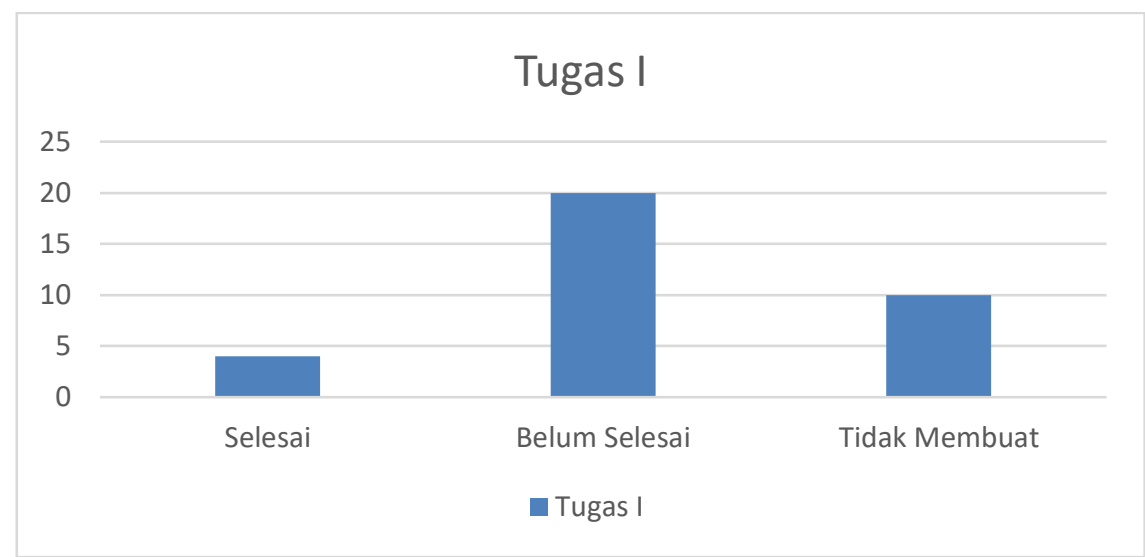

Gambar 1. Grafik Penyelesaian Tugas I

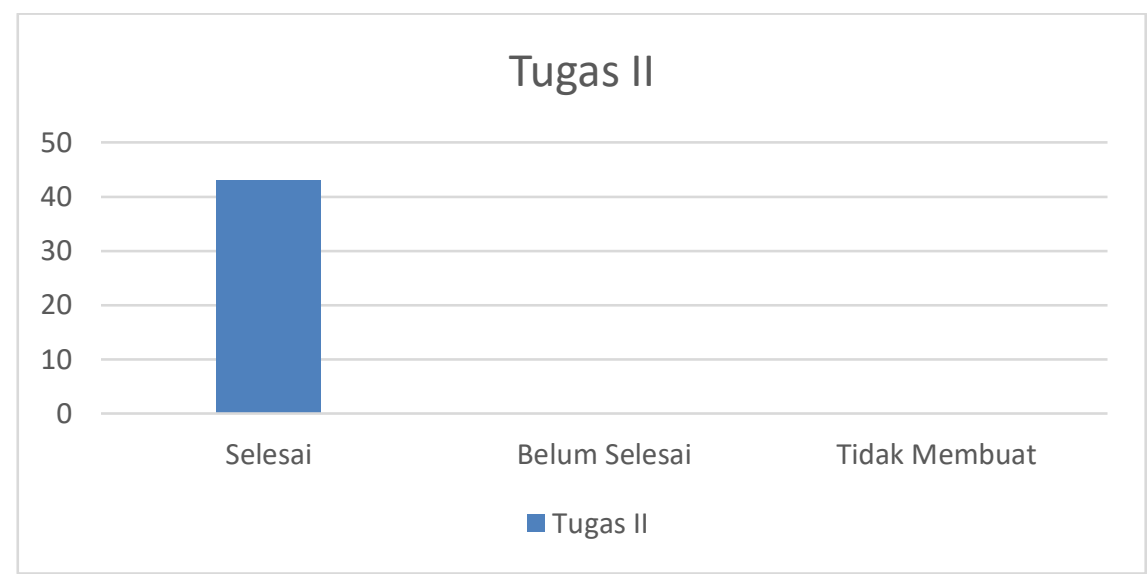

Gambar 2. Grafik Penyelesaian Tugas II

Dari hasil penelitian diperoleh data bahwa pada Tugas I dalam bentuk tulisan materi tentang perubahan social menunjukkan bahwa siswa di kelas IX-I dengan jumlah 34 siswa yang mampu menyelesaikan tugas sebanyak 4 siswa (12\%), siswa yang mengerjakan tugas namun belum selesai sebanyak 20 siswa (59\%) dan siswa yang tidak mengerjakan tugas sebanyak 10 siswa (29\%). Pada Tugas ke II kegiatan pembelajaran menggunakan RPP Integratif dengan mata pelajaran lain yaitu IPS, PPKn, PAI, Bahasa Indonesia dan Seni Budaya dengan tema Perkembangan Politik di Indonesia menunjukkan jumlah siswa yang menyelesaikan tugas sebanyak 34 siswa.

Kegiatan pembelajaran ini dilakukan di aula sekolah di dampingi oleh Bapak Kepala sekolah, Komando Rayon Militer 0828/01 Kabupaten Sampang, Guru Bimbingan Konseling, serta semua guru mata pelajaran yang terintegrasi dalam RPP Integrasi.

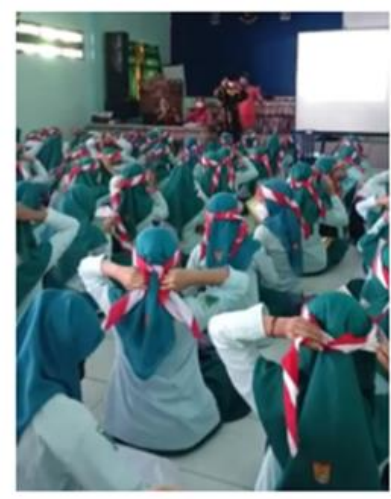

Gambar 1 Persiapan Pemutaran Film G30S/PKI, siswa melakukan pemasangan Hasduk di kepala. 


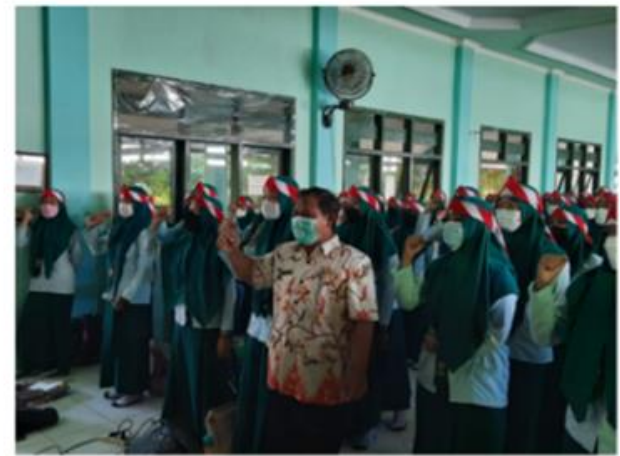

Gambar 2 Ice Breaking, menynayikan lagu Maju Tak Gentar

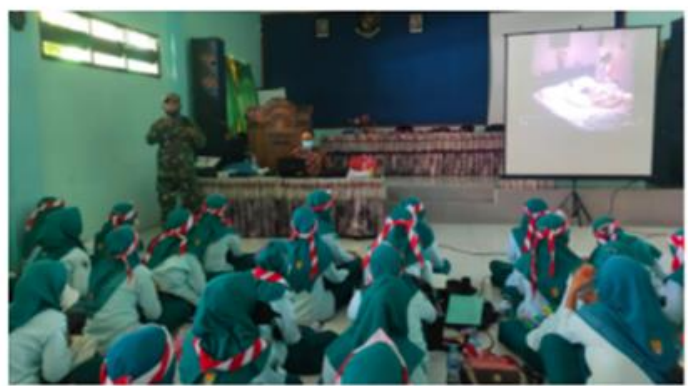

Gambar 3 Pendampinga dari Komando Rayon Militer 0828/01 Kabupaten Sampang
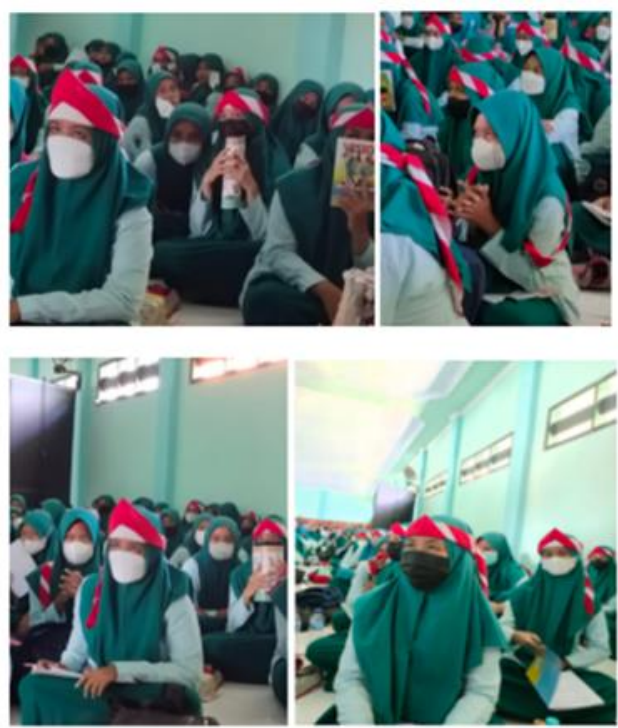

Gambar 4. Acara Inti menonton Film G30S/PKI

\section{Pembahasan}

Berdasarkan tabel tersebut di atas dapat dikatakan budaya literasi di SMP Negeri 1 Sampang sangat rendah sekali kemampuan siswa dalam menyelesaikan tugas laporan tertulis sampai dengan selesai pada tugas I dari 34 siswa diperoleh data $12 \%$ siswa yang mampu menyelesaikan tugas, $59 \%$ belum selesai mengerjakan dan $29 \%$ siswa tidak mengerjakan tugas.

Ketidakmampuan siswa dalam menyelesaikan tugas disebabkan karena (1) kurangnya minat siswa dalam membaca (2) siswa cenderung bergantung pada pada aplikasi aplikasi yang dapat memberikaan jawaban langsung terhadap masalah - masalah yang harus dipecahkan. sehingga untuk membuat tulisan mereka sulit untuk mengembangkannya yang memunculkan rasa malas sehingga tugas tugas yang diberikan oleh guru tidak terselesaikan.

Agar budaya literasi sekolah dapat diwujudkan maka seorang guru perlu melakukan inovasi pembelajaran dengan mencitakan strategi pemebalajaran yang lebih menyenangkan . 


\section{Vol. 1 No. 2 September 2021 e-ISSN : 2797-3344 P-ISSN : 2797-3336}

Menurut Arthur (1963) dalam (Rahmayanti 2016) menyatakan perasaan suka akan menjadi minat yang akan bereaksi terhadap suatu yang khusus atau kondisi tertentu. Seseorang yang memiliki rasa suka terhadap sesutu akan meningkatkan minatnya terhadap sesuatu tersebut. Misalkan siswa yang menyukai kegiatan pembelajaran maka akan meningkatkan minat belakjarnya. Strategi yang penulis lakukan yaitu membuat RPP Integratif dengan mata pelajaran yang lain yaitu IPS, PPKn, PAI,Bahasa Indonesia dan Seni Budaya dalam satu tema pokok yaitu perkembangan politik di Indinesia dengan media pembelajaran menonton film dokumenter peristiwa G30S/PKI.

Strategi yang penulis ambil untuk mewujudlan literasi sekolah dengan melakukan kegiatan pembelajaran dengan mengintegrasikan beberapa mata pelajaran lain dan dipadukan dalam satu tema materi pokok yaitu perkembangan politik di Indonesia. Dalam kegiatan ini siswa diminta untuk melakukan kegiatan menganalisa materi pelajaran dengan media pembelajaran menonton film dokumenter peristiwa G30/PKI. Kegiatan ini membuat siswa senang karena pembelajaran tidak lagi monoton mendengarkan informasi dari guru. Demikian pula pada kegiatan pembelajran dengan menggunakan RPP Integratif membuat anak menjadi senang, minat belajar menjadi meningkat dan tugas terselesaikan dengan baik. serta mendapatkan informasi kegiatan pembelajaran menggunakan RPP Intergratif merupakan kegiatan pembelajaran yang menyenangkan dan adanya perpaduan materi pelajaran yang menyebabkan tidak ada lagi pengkotakan antara materi yang satu dengan materi yang lainnya. RPP Integratif ini juga meningkatkan motivasi siswa dalam belajar dan meningkatkan siswa dalam berpikir kreatif dan kritis.

\section{KESIMPULAN}

Berdasarkan hasil penelitian dan pembahasan tentang Implementasi RPP Integratif Membentuk Karakter untuk Mewujudkan Budaya Litersi Sekolah dapat dikatakan sebagai kegiatan pembelajaran yang sangat tepat. Kegiatan literasi sekolah yang awalnya begitu sulit diterapkan di sekolah menjadi mudah dikerjakan oleh siswa karena kegiatan pembelajaran yang menyenangkan, siswa merasakan kerbermaknaan dalam kegiatan pembelajaran dengan RPP Integratif. RPP Integratif ini memiliki banyak manfaat baik bagi guru maupun siswa. Contextual Teaching Learning diperoleh siswa menyebabkan siswa lebih antusias dalam menggali informasi di luar kegiatan sekolah karena tidak ada lagi pengkotakan materi pelajaran, siswa menjadi lebih berpikir kritis dalam menyelesaikan masalah kehidupan, dan siswa tidak lagi terbebani dengan tugas di setiap mata pelajaran. kegiatan ini memberikan motivasi kepada guru untuk lebih kreatif dalam mencari tema-tema integratif baru dengan mata pelajaran lain, Dengan kegiatan pembelajaran menggunakan RPP Integratif ini menunjukkan adanya peningkatan yang luar biasa dalam siswa berliterasi di sekolah. Terbukti dari tugas I siswa yang mampu menyelesaikan tugas laporan tertulis $12 \%$ dari 34 siswa pada tugas II siswa yang menyelesaikan tugas $100 \%$ dari 34 siswa.

\section{DAFTAR PUSTAKA}

Agustin, S., \& Cahyono, B. E. H. (2017). Gerakan Literasi Sekolah untuk Meningkatkan Budaya Baca di SMA Negeri 1 Geger. Linguista: Jurnal Ilmiah Bahasa, Sastra, Dan Pembelajarannya, 1(2), 55. https://doi.org/10.25273/linguista.v1i2.1973

Ane, P. 2015. Membangun kualitas bangsa dengan budaya literasi.Prosiding Seminar Nasional Bulan Bahasa UNIB 2015

Kemdikbud. (2016). Panduan Gerakan Literasi Sekolah di Sekolah Dasar. https://doi.org/10.1007/s10029- 017-1595-x

Antasari, I. W. 2017. Implementasi Gerakan Literasi Sekolah Tahap Pembiasaan di MI Muhammadiyah Gandatapa Sumbang Banyumas. Libria, 9 (1), 13-26

Prasetyono, D.S. (2008). Rahasia Mengajarkan Gemar Membaca pada Anak Sejak Dini. Yogyakarta: Think Yogyakarta

Wandasari, Y. 2017. Implementasi Gerakan Literasi Sekolah (GLS) Sebagai Pembentuk 
Vol. 1 No. 2 September 2021 e-ISSN : 2797-3344 P-ISSN : 2797-3336

Pendidikan Berkarakter. JMKSP (Jurnal Manajemen, Kepemimpinan, Dan Supervisi Pendidikan), 2 (2), 12-22. 